DOI: 10.20472/IAC.2017.031.049

\title{
PETER STANWICK
}

Auburn University, United States

\section{SAMSUNG'S GALAXY NOTE 7: HOW A PRODUCT CAN GO UP IN SMOKE}

\begin{abstract}
:
On August 2, 2016, Samsung announced its new smartphone, the Galaxy Note 7. A month later, Samsung recalled 2.5 million Galaxy Note $7 \mathrm{~s}$ due to the phones catching on fire. By October 2016, Samsung permanently discontinued the Galaxy Note 7 smartphone.

The purpose of this case is to examine how Samsung addressed the needs of its stakeholders in the introduction and subsequent recall of the Galaxy Note 7. From a stockholder perspective, Samsung was under pressure to produce a phone to rival the iPhone and have it to market before Apple could launch a new product. They succeeded with this goal since the iPhone 7 was not introduced until September 7, 2016. From a customer perspective, Samsung did not believe that there was a problem with the phone until customer protests forced Samsung to react. In addition, airlines, based on the recommendation by the Federal Aviation Administration, banned customers from carrying a Galaxy Note 7 onboard airplanes. From an employee's perspective, there were fundamental flaws in the design of the smart phone, yet the quality issues were not resolved until after the recall occurred. For Chinese customers, Samsung delayed the recall by claiming that the defective batteries were not included in the Chinese market. In addition, once the phones were recalled, the replacement batteries also generated overheating and a shortened battery life. From a supplier perspective, Samsung concluded that the lithium-ion battery in the phone would overheat and create the fire. One of the suppliers of the batteries was Samsung SDI. From a global governmental regulatory perspective, Samsung was slow to react to the government regulations regarding the recall of a potentially dangerous product. Furthermore, the United States Consumer Product Safety Commission recommended that consumers immediately stop using the Galaxy Note 7 once the information pertaining to the fires became public.

As a result, this case study will highlights the strengths and weaknesses of Samsung's attempt to address the needs of its stakeholder during this product crisis.
\end{abstract}

\section{Keywords:}

Samsung; Recall; Stakeholders 